\section{Extra small metacentric chromosome identified as $\mathrm{i}(18 \mathrm{p})$}

SUMMARY A case of a supernumerary metacentric small chromosome, diagnosed at birth, is described. The cytogenetic findings support its identification as $\mathrm{i}(18 \mathrm{p})$. The clinical development from birth to 12 months is reported, with particular attention given to the psychomotor retardation and to the immunological aspect.

Many cases of a supernumerary small metacentric chromosome have been reported in the literature, but their diagnosis has rarely been made during the perinatal period. In this paper we report a case of $\mathrm{i}(18 \mathrm{p})$ diagnosed at birth, and clinical development up to the present age of 12 months is described.

\section{Case report}

The proposita was a female born at 39 weeks' gestation by caesarian section because of breech presentation after an uneventful pregnancy. The mother, gravida 1 , had diabetes $B$, and both she and the father were 35 years old at the time the child was born. The parents were not related. The proposita, whose birthweight was $2500 \mathrm{~g}$ ( $<3$ rd centile), had no perinatal problems: cardiotocography and Apgar score were normal. The physical examination showed low set ears, micrognathia, prominent occiput, epicanthic folds, triangular mouth, and hypertonia of the limbs with opisthotonos (Fig. 1). Because of the neurological findings, instructions for care were given to the mother when the child was discharged. At one month old she was sent to a physiotherapy centre. At three months, she had vomiting and eczema due to cow's milk allergy

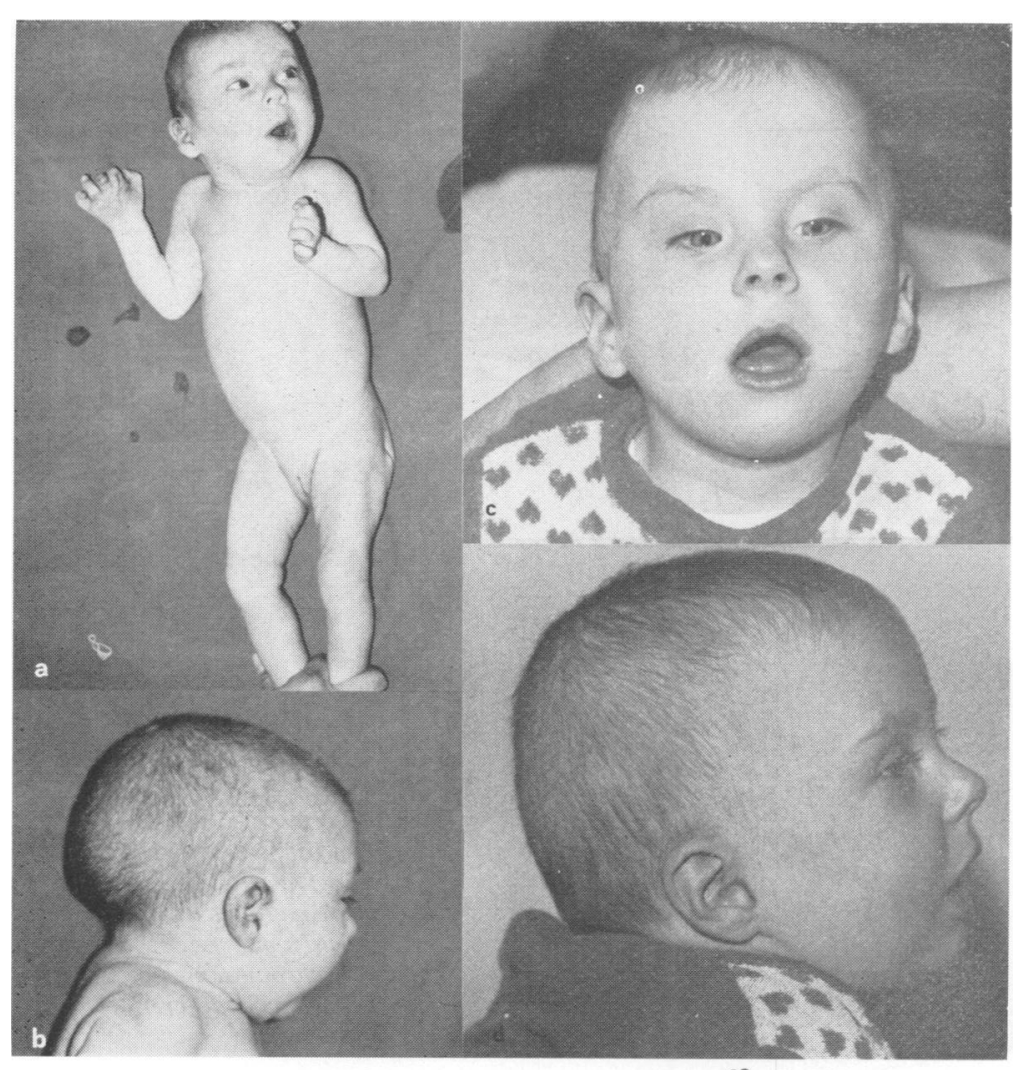

69
Fig. 1 The proposita $(a, b)$ at birth, $(c, d)$ at 12 months. 
associated with $\operatorname{IgA}$ deficiency, and therefore dietetic therapy was introduced. In spite of the physiotherapy and stimulation, the psychomotor development, periodically controlled, deteriorated with persistence of hypertonia and spasticity.

Electroencephalogram, examination of the fundus oculi, audiometry, urine and blood aminoacid levels, serum IgM and IgG, urinary mucopolysaccharides, skeleton $x$-ray, and urography were all normal.

The more significant clinical data are summarised in the Table.

\section{CYTOGENETIC FINDINGS}

Chromosome investigations were performed in the first week of life on stimulated peripheral lymphocytes, and the metaphases thus obtained were analysed according to our standard method: the

Table Summary of the more significant clinical data

\begin{tabular}{|c|c|c|c|}
\hline & 3 months & 6 months & 12 months \\
\hline $\begin{array}{l}\text { Weight (centile) } \\
\text { Length (centile) } \\
\text { Head circumference } \\
\text { Hypertonia } \\
\text { Brunet-Lézine } \\
\text { EEG } \\
\text { IgA (mg\%) } \\
\text { E-Rosette forming cells } \dagger \\
\text { IgA-producing } \\
\text { lymphocytes* }\end{array}$ & $\begin{array}{l}<3 \text { rd } \\
<3 \text { rd } \\
<3 \text { rd } \\
+ \\
\text { NT } \\
\text { N } \\
10 \\
\text { NT } \\
\text { NT }\end{array}$ & $\begin{array}{l}3 \mathrm{rd} \\
25 \mathrm{th}-50 \mathrm{th} \\
3 \mathrm{rd}-10 \mathrm{th} \\
+ \\
4 \mathrm{~m} 21 \mathrm{~d} \\
\mathrm{~N} \\
7 \\
50 \% \\
6 \%\end{array}$ & $\begin{array}{l}\text { 3rd-10th } \\
75 \text { th } \\
10 \text { th-25th } \\
+ \\
6 \mathrm{~m} \\
\mathrm{~N} \\
35 \\
63 \cdot 7 \% \\
\text { NT }\end{array}$ \\
\hline
\end{tabular}

a
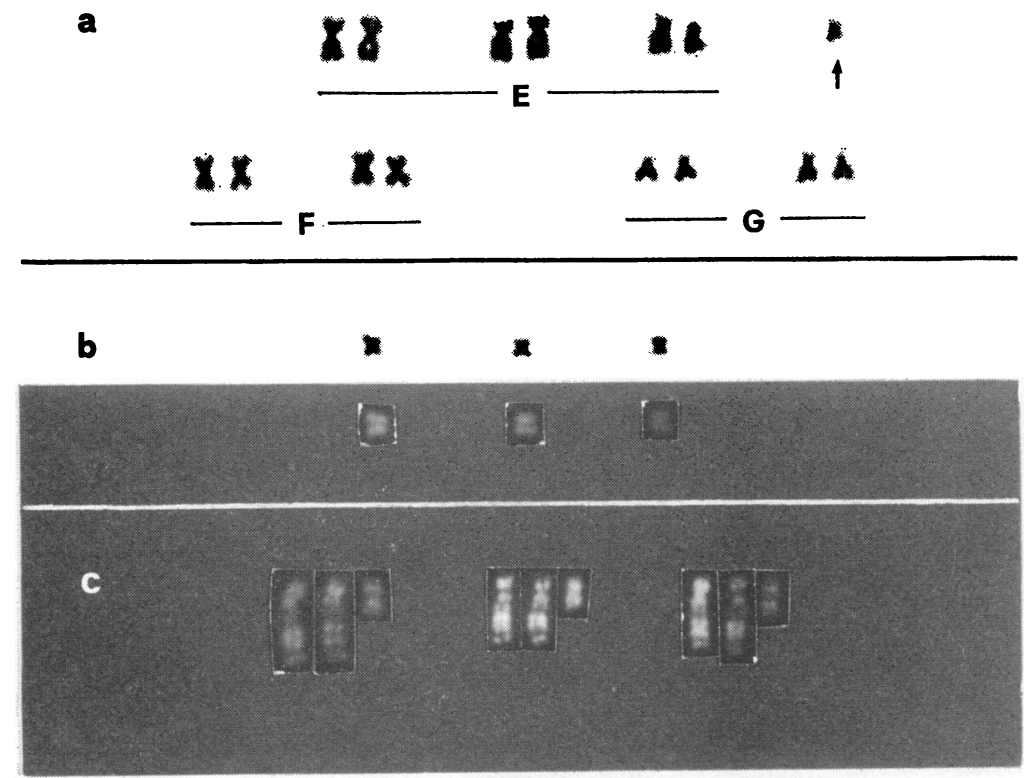

Fig. 2 (a) Proposita's partial karyotype. (b) Single marker chromosome stained first with Giemsa (upper row) and then with $Q M$ (bottom row) from $3 \propto$ different metaphases. (c) Proposita's pair no. 18 and marker chromosomes after $R B$ banding from 3 different metaphases.

and then with quinacrine mustard.

These examinations showed a karyotype of $47, X \overline{\bar{\alpha}}$, + mar, in which the supernumerary chromosorge was represented by a small metacentric chromosone. in finding was present in all of more than a hundred secondary constriction or satellites and was neker involved in acrocentric associations. The partial karyotype (Fig. 2a) shows the morphological aspect. Since Q-banding (Fig. 2b) did not produee decisive evidence either, we used the technique of R-banding by BUdR using acridine orange (RBA) somes and from the effect of the BUdR made $\rightarrow$ (18p). that the marker was an isochromosome for the shert arms of acrocentrics, or a remnant of Robertsonien

(1) The Ag-As technique (Bloom and Goodpasture, 1976), which is specific for the NQd (Ferraro et al., 1977) (Fig. 3a). Since it is very rare to find all the acrocentrics Ag-stained gn the same metaphase, we analysed more thin 50 metaphases from 4 different slides to $8 e$ The distamycin A/DAPI technique (Schweizer 
a
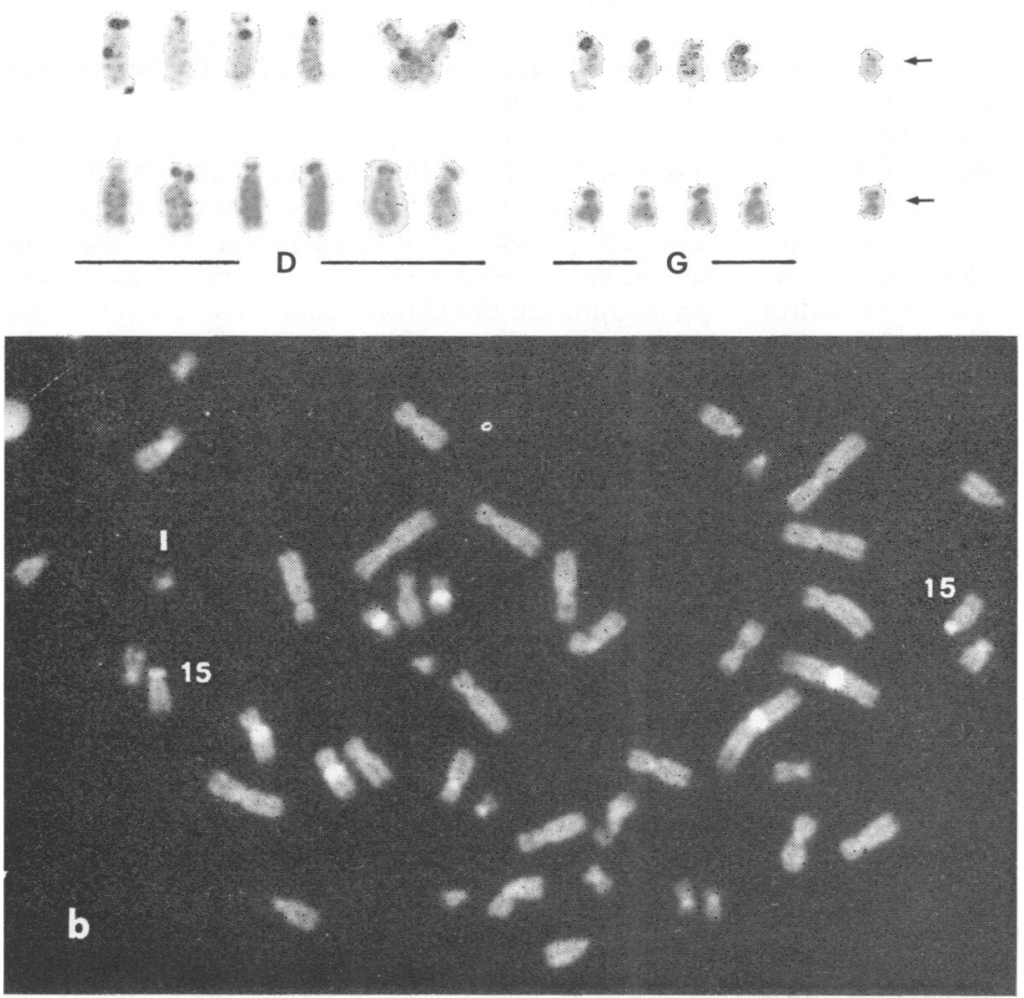

c

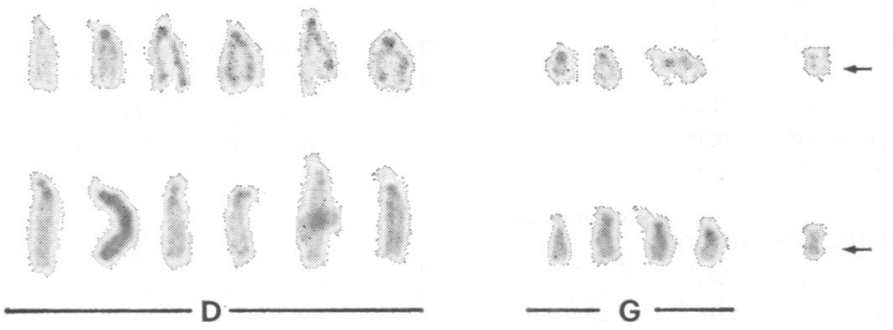

Fig. 3 (a) Ag-As technique: $D$ and $G$ group chromosomes plus marker from 2 different metaphases. (b) Metaphase stained with distamycin $A$ plus DAPI technique. The arrow indicates the marker. (c) $D$ and $G$ group chromosomes plus marker from 2 different metaphases, Giemsa-11 stained.

et al., 1978) which stains, in acrocentrics, the short arm of chromosome 15 (Fig. 3b). We used this technique because most additional small metacentric chromosomes are thought by some authors to be isochromosomes for the $15 \mathrm{p}$.

(3) The Giemsa-11 technique (Bobrow et al., 1972), which stains, besides the 9qh, " the short arms and sometimes the satellites of all $D$ and G group chromosomes' (Fig. 3c). The marker was not stained by any of these techniques. The karyotype of both parents was normal.

\section{DERMATOGLYPHS}

All digital patterns were ulnar loops, except for radial loops on both the 2 nd digits and a whorl on the left 4th digit. A bilateral simian crease was present and an additional flexion fold in the right 2nd digit was found between the two interphalangeal ones.

\section{Discussion}

The cases of a supernumerary small metacentric chromosome described before the introduction of 
banding techniques show a remarkable variability of phenotypes. Some cases had a normal phenotype, while others had serious anomalies (Dzarlieva et al., 1975). This caused the assumption that there was not a specific syndrome resulting from the small metacentric chromosome and that the variability of the clinical aspects depended on the origin of the extra chromosome. The cases described after the introduction of banding techniques confirmed this hypothesis. In fact, cases have been described of the extra chromosome being identified as $i(18 p)$ (Condron et al., 1974), 18q - (Fujita and Fujita, 1975), i(17p) (Nielsen et al., 1977), 17q- (Palutke et al., 1976), and isochromosome of the short arm of an acrocentric chromosome or remains of a Robertsonian fusion (Nielsen and Hreidavsson, 1973).

In our case the cytogenetic data can be summarised as follows:

(1) The extra chromosome is symmetrical and the length of the two arms corresponds to the length of the $18 \mathrm{p}$.

(2) The fluorescence in Q-bands is also symmetrical and comparable to that of the $18 \mathrm{p}$.

(3) The RBA bands show a distinct pattern which is also symmetrical and always in accordance with that of the $18 \mathrm{p}$.

(4) Finally, the marker was not stained by specific techniques for the short arms of acrocentrics. The most likely hypothesis is, therefore, that the extra chromosome is an isochromosome for the short arm of the 18. This hypothesis is also the simplest, since it only resorts to the misdivision of the centromere of a chromosome 18 in order to explain the origin of the aneuploidy.

The most probable alternative hypothesis, trisomy of $18 \mathrm{q}-$, presupposes a split in $18 \mathrm{q}$ and nondisjunction in the first meiotic division, that is, at least two distinct events.

It should also be remembered that the formation of an isochromosome is not a rare occurrence in man, as numerous cases of $\mathrm{i}(\mathrm{Xq})$ found in published reports show.

Many of the cases of $i(18 p)$ reported so far are in adults who, apart from psychomotor retardation, do not present other serious defects which limit their life span. Besides, as far as we know, no cases of $i(18 p)$ in spontaneous abortions have ever been reported (Boué et al., 1976). Such statements suggest that the chromosomal imbalance as a result of $i(18 p)$ is not very serious, perhaps because of the small size of the $18 \mathrm{p}$ and/or because in this area there are no important genes, and that the functions of the central nervous system are the first to be compromised in the presence of an autosomic derangement.

As regards the clinical data (Table), the little girl born small-for-dates, has shown normal growth in $\widehat{D}$ both head circumference and body length. Weight: recovery was delayed because of the cow's milk $\stackrel{\vec{s}}{\rightarrow}$ protein allergy, which was sustained by the presenceo of anti-milk protein antibodies in the serum. A normal increase in body weight occurred after the $\frac{\bar{c}}{\frac{5}{5}}$ introduction of the elimination diet at 5 months.

The presence of serious psychomotor retardation and the persistence of hypertonia with signs of ${ }^{\infty}$ spasticity, accompanied by a normal electroence- $\vec{\circ}$ phalogram are the clinical data most in accordance $\overrightarrow{\vec{\omega}}$ with the data reported in other reports; these features $\omega$ persisted in spite of immediate treatment (stimulation and physiotherapy).

As regards the immunological data, at 6 months $\vec{\sigma}$ we found low serum IgA and normal serum IgA- $-\overrightarrow{-}$ producing lymphocytes. This finding pointed towards 8 a temporary immunological deficiency, which was은 confirmed by complete return to normal at $12-$ months. The evaluation of the cellular immunity ${ }_{\infty}$ showed a slight defect $(50 \%$ of E-Rosette-forming을

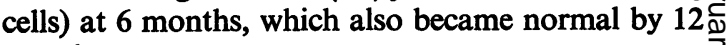
months.

Ogata et al. (1977) reported low IgA at 6 months $\vec{\varphi}$ in a similar case. In the published reports we found $\circlearrowleft$ no other references to immunological development in cases of $i(18 p)$. Nevertheless, vomiting and nutritionalo difficulties, not infrequently reported, suggest that initial immunological deficiency is not an unusual finding.

\section{MARIANO ROCCHI ${ }^{1}$, MARINO STORMI ${ }^{2}$, NICOLETTA $\overline{\overline{0}}$ ARCHIDIACONO ${ }^{1}$, AND GIORGIO FILIPPI ${ }^{1}$ \\ Cattedra di Genetica Medica ${ }^{1}$ e Cattedra di Puericultura ${ }^{2}$, Università di Trieste- Istituto per l'Infanzia di Trieste, Via dell' Istria 65, 34137 Trieste, Italy:}

\section{References}

Bloom, S. E., and Goodpasture, C. (1976). An improved technique for selective silver staining of nucleolar organizero regions in human chromosomes. Human Genetics, 34, 199-206.

Bobrow, M., Madan, K., and Pearson, P. L. (1972). 으․ Staining of some specific regions of human chromosomes,$\sqrt{\mathrm{N}}$ particularly the secondary constriction of no. 9. Nature,

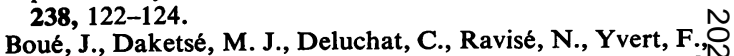
and Boué, A. (1976). Identification par les bandes Q et GCU des anomalies chromosomiques dans les avortementso spontanés. Annales de Génétique, 19, 233-239.

Condron, C. J., Cantwell, R. J., Kaufman, R. L., Brown S. B., and Warren, R. J. (1974). Medical Genetics Today pp. 36-42. Ed. by D. Bergsma. Birth Defects: Original Article Series, X, No. 10. The National FoundationMarch of Dimes, New York.

Dzarlieva, R., Efinski, D., and Šopova, M. (1975). Genetiō prognosis and counselling in the presence of extra smal尺 chromosomes. Journal de Génétique Humaine, 23, 197-206@ 
Ferraro, M., Archidiacono, N., Pelliccia, F., Rocchi, M., Rocchi, A., and de Capoa, A. (1977). Secondary constrictions and nucleolus organizer regions in man. Experimental Cell Research, 104, 429-430.

Fujita, K., and Fujita, H. M. (1975). An extra small submetacentric chromosome: possible partial 18 trisomy. Japanese Journal of Human Genetics, 19, 371-373.

Nielsen, J., Homma, A., and Holm, V. (1977). Inversion 19 and isochromosome short arm 17 or 18. Human Genetics, 37, 347-350.

Nielsen, J., and Hreidavsson, A. B. (1973). Father and daughter with presumptive isochromosome satellitesshort arms D or G. Humangenetik, 19, 271-274.

Ogata, K., Iinuma, K., Kamimura, K., Morinaga, R., and Kato, J. (1977). A case report of a presumptive $+i(18 p)$ associated with serum IgA deficiency. Clinical Genetics, 11, 184-188.

Palutke, W., Chen, H., Woolley, P., Jr., Espiritu, C., Vogel, H. L., Gohle, N., and Tyrkus, M. (1976). An extra small metacentric chromosome identified as a deleted chromosome no. 17. Clinical Genetics, 9, 454-458.

Schweizer, D., Ambros, P., and Andrie, M. (1978). Modification of DAPI banding on human chromosomes by prestaining with a DNA-binding oligopeptide antibiotic, distamycin A. Experimental Cell Research, 111, 327-332.

Requests for reprints to Dr Mariano Rocchi, Istituto per l'Infanzia, Via dell'Istria 65,34137 Trieste, Italy.

\section{Familial dicentric translocation $\mathrm{t}(13 ; 18)(\mathrm{p} 13 ; \mathrm{p} 11.2)$ ascertained by recurrent miscarriages}

SUMMARY A dicentric translocation is described involving chromosomes 13 and 18 in which the centromere of chromosome 13 was suppressed. The translocation was ascertained by repeated miscarriages and was found in three generations of phenotypically normal carriers.

Familial dicentric translocations have not been reported in man other than in Robertsonian fusions (Daniel and Lam-Po-Tang, 1976). Other dicentric translocations have been described involving at least one non-acrocentric chromosome. The latter,

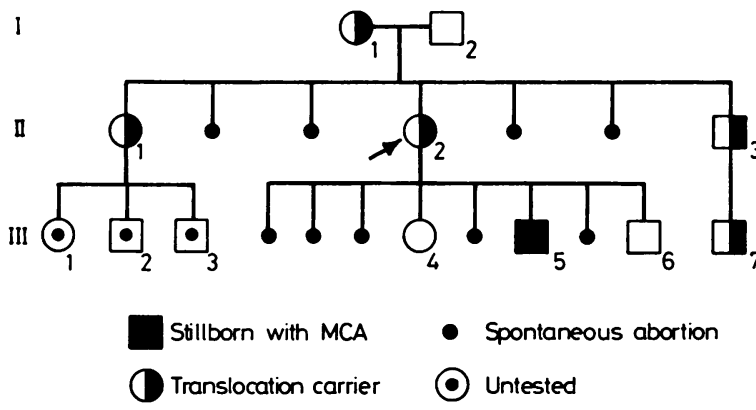

Fig. 1 Pedigree. 